\title{
CIDADANIA EM TRANSFORMAÇÃO: UM PANORAMA DOS PROBLEMAS ATUAIS
}

\section{CITIZENSHIP IN CHANGE: AN OVERVIEW OF ITS CURRENT PROBLEMS}

\author{
José Rodrigo Rodriguez \\ Universidade do Vale do Rio dos Sinos - Unisinos - (São Leopoldo, RS, Brasil)
}

Recebimento: 2 mar. 2017

Aceitação: 11 ago. 2017

\begin{abstract}
Como citar este artigo / How to cite this article (informe a data atual de acesso / inform the current date of access):
\end{abstract}
RODRIGUEZ, José Rodrigo. Cidadania em transformação: um panorama dos problemas atuais. Revista da Faculdade de Direito UFPR, Curitiba, PR, Brasil, v. 62, n. 3, p. 61-79, set./dez. 2017. ISSN 2236-7284. Disponível em: $<$ http://revistas.ufpr.br/direito/article/view/50979>. Acesso em: $21 \quad$ dez. $2017 . \quad$ DOI: http://dx.doi.org/10.5380/rfdufpr.v62i3.50979.

\section{RESUMO}

O objetivo deste artigo é apresentar as características do conceito de cidadania e as transformações por ele enfrentadas no mundo contemporâneo, a partir da visão inovadora de Andreas Niederberger. Em sua primeira parte, o texto apresenta as características centrais da cidadania na visão tradicional, apontando sua importância para a política e a sua relação com as ideias de representação e desigualdade social, com referência nos autores clássicos para o estudo do tema. A seguir, o artigo aponta os maiores desafios enfrentados pelo conceito no mundo contemporâneo e as principais soluções levantadas para tais desafios. Neste ponto, o artigo analisa as implicações, sobre o conceito de cidadania, de fenômenos como a criação de ordens normativas privadas transnacionais, o trabalho temporário em um determinado território, o domínio do capital financeiro e as migrações internacionais. Finalmente, o texto expõe a solução defendida por Niederberger, que desenvolve a sua visão de cidadania a partir da ideia de cidadania-constelação, defendendo que o conceito é capaz de manter sua utilidade em um mundo composto de ordens normativas plurais.

\section{PALAVRAS-CHAVE}

Estado. Cidadania. Representação. Globalização. Transformação.

\begin{abstract}
The aim of this article is to present the characteristics of the concept of citizenship and the transformations it faces in the contemporary world, based on the innovative vision of Andreas Niederberger. In its first part, the text presents the central characteristics of citizenship in the traditional view, pointing out its importance for politics and its relation with the ideas of representation and social inequality based on classic authors for the theme. Next, the article points out the major challenges faced by the concept in the contemporary world and the main solutions raised for such challenges. At this point, the article analyzes the implications for the concept of citizenship of phenomena such as the creation of transnational private normative orders, temporary work in a given territory, the domination of finance capital and the international migrations. Finally, the text exposes the solution defended by Niederberger, who develops his vision of citizenship based
\end{abstract}


on the idea of "citizenship-constellation", arguing that the concept is capable of maintaining its usefulness in a world composed of plural normative orders.

\section{KEYWORDS}

State. Citizenship. Representation. Globalization. Change.

\section{INTRODUÇÃO}

A cidadania tem funcionado como uma modalidade de pertencimento a ordens políticas nacionais que provê aos cidadãos e cidadãs uma série de direitos, bens e serviços, principalmente a possibilidade de participar da formação das normas que compõem a referida ordem política. Ser cidadão ou cidadã de um país implica ser titular de um determinado status jurídico composto de uma série de direitos e deveres destinados exclusivamente a essas pessoas.

Como nos ensina Andreas Niederberger (2015), boa parte do debate sobre cidadania tem se concentrado no conteúdo desse status jurídico, tendo como finalidade diferenciar as várias concepções de democracia; por exemplo, a visão liberal e a visão republicana, que serão examinadas a seguir. A maior parte das análises tem deixado de lado a dimensão de pertencimento que caracteriza a cidadania e o conflitos políticos e sociais relativos a tal status.

A compreensão das mútuas relações entre cidadania, Estado nacional e a eventual possibilidade de criar uma sociedade global é o que nos permitirá compreender melhor as características e desafios da cidadania no mundo contemporâneo. Afinal, depois de ao menos trinta anos de estudos sobre o fenômeno da globalização, não é razoável abordar os problemas da cidadania no mundo de hoje sem levar em conta a globalização das relações sociais e a financeirização do capitalismo, fenômenos que, como veremos, parecem estar destruindo os pressupostos políticoinstitucionais da existência da cidadania como a conhecemos até hoje.

Assim, não se trata de debater apenas qual é ou qual deveria ser o conteúdo da cidadania: é preciso discutir também o seu lugar privilegiado na gramática da política e do direito contemporâneo. Em outras palavras, trata-se de debater se o conceito de cidadania como o conhecemos é capaz de abarcar hoje uma série de modalidades de pertencimento que se referem não apenas às comunidades políticas estatais, mas também a ordens normativas de outra natureza, surgidas ao redor do globo. Como veremos, tais ordens normativas estão pondo em xeque as fronteiras estatais como condição e limite para o exercício da cidadania no mundo de hoje.

Por um lado, a imigração crescente e a presença temporária de homens e mulheres no interior de diversos Estados, em temporadas de trabalho e estudo, mostram como a cidadania ainda é monopólio dos nacionais dos Estados, sendo incapaz de dar voz a todas as pessoas que sofrem os 
efeitos das normas criadas no âmbito de uma determinada ordem política. Olhando o problema por essa perspectiva, deparamo-nos com pessoas que sofrem efeitos de normas sobre as quais não têm poder de influência algum; efeitos os quais podem se protrair no tempo, por exemplo, no caso de nacionais de um país que trabalham ou estudam em países próximos por períodos longos.

De outro lado, uma série de problemas sociais estão saindo do controle da vontade política dos cidadãos e cidadãs, como por exemplo o controle sobre as transações financeiras internacionais, as questões ambientais e a regulação da atividade das empresas transnacionais. Atividades como essas produzem um conjunto de regras próprias, as quais tendem a escapar do poder de influência dos cidadãos e cidadãs nacionais, pondo em questão o poder dos Estados e a capacidade do regime democrático de garantir a participação de todas as pessoas na produção das normas que influenciam as suas vidas.

A cidadania se mostra, assim, em suma, no primeiro caso, como um instrumento de discriminação injusto; um instrumento de dominação não democrático e, no segundo caso, como um instrumento ineficaz para que homens e mulheres determinem autonomamente o seu destino.

Para dar conta de todas essas questões, abordaremos neste texto, inicialmente, a relação entre cidadania, democracia e Estado de direito em sua forma clássica, ou seja, a cidadania referida às fronteiras dos Estados nacionais. Em seguida, apontaremos os principais desafios da cidadania no mundo contemporâneo e suas alternativas, que passam pelo debate sobre a possibilidade ou não da formação de uma sociedade mundial, ou seja, um regime político que funcione para além dos limites territoriais dos Estados nacionais ou, ainda, de um regime que promova uma articulação complexa entre ordens normativas organizadas em múltiplos níveis, Estados nacionais inclusive.

Logo em seguida, apresentaremos as principais propostas teóricas existentes no debate contemporâneo, que pretendem manter o conceito de cidadania como parte da gramática da política contemporânea, ainda que com reformulações, quais sejam, na formulação de Niederberger, a cidadania cosmopolita, a filiação política sem cidadania e a cidadania-constelação. Finalmente, na última parte deste texto, retomaremos a discussão das suas duas primeiras partes, para reforçar as ligações entre os principais conceitos aqui discutidos e mostrar as possibilidades teóricas e práticas da ideia de uma cidadania-constelação, proposta por Niederberger para fazer frente aos problemas enfrentados pela cidadania no mundo contemporâneo. 


\section{CIDADANIA, DEMOCRACIA E ESTADO DE DIREITO}

O debate atual sobre a cidadania concentra-se na definição de seu conteúdo, deixando em segundo plano seu significado como forma de pertencimento a uma comunidade política. Assim, para a visão liberal de cidadania, ser cidadão significa poder exercitar a escolha livre na maior parte dos âmbitos de sua vida (NIEDERBERGER, 2015, p. 84). De acordo com esta posição, uma ordem política será considerada legítima se permitir que as pessoas decidam livremente, sem entraves externos à sua vontade, sobre os problemas que os afetam.

O único limite legítimo à vontade individual, para a visão liberal, é aquele que vise a garantir que a mesma parcela de liberdade possa ser exercitada por todas as pessoas. O exercício da minha liberdade, portanto, não pode ser um empecilho para que outras pessoas possam exercer a sua: daí a necessidade de criar alguns limites para a liberdade dos cidadãos e cidadãs. Por exemplo, a criação de um poder policial, visto dessa perspectiva, tem como objetivo impedir que indivíduos ou grupos tomem as leis em suas mãos e, com uso de violência, dominem os demais.

Da mesma maneira, o controle da concorrência nos mercados pode ser visto como uma forma de evitar a formação de grandes conglomerados empresariais, suficientemente poderosos para manipular as regras do mercado livre e prejudicar injustamente empresas menores. De um outro ponto de vista, para além da questão dos mercados, a existência de poderes privados arbitrários, ou seja, de poderes que determinem a vida das pessoas com fundamento em argumentos, entre outros, científicos e morais, sem que essas pessoas afetadas possam tomar parte na criação de suas normas, também entra na mira da versão liberal da cidadania, a qual pretende garantir a liberdade individual acima de tudo.

Para uma visão republicana da cidadania, seguindo aqui a exposição de Niederberger (2015, p. 84), seu conteúdo pode variar com as ordens políticas historicamente consideradas sem que haja uma ligação especial entre cidadania e liberdade. De acordo com esse modo de ver o problema, a liberdade individual é apenas uma das dimensões da cidadania, uma dimensão central sem dúvida, mas que precisa ser conjugada com outros valores sociais.

A centralidade da liberdade individual, assim, residiria na necessidade de que o conteúdo da cidadania e, portanto, as normas que compõem a ordem política como um todo, resultem da vontade de seus membros. Os republicanos e republicanas admitem, portanto, que as escolhas individuais sejam limitadas em nome do bem comum, desde que tais limitações sejam resultado da vontade de todas as pessoas, apurada por intermédio do sistema político. 
Com efeito, para essa visão, eventuais limitações à liberdade individual não afetariam o direito de liberdade, pois, por exemplo, seria necessário garantir um determinado grau de igualdade para que a liberdade possa ser, de fato, exercitada. Tal argumento, clássico, como é sabido, remonta a Jean-Jacques Rousseau (1989) e Karl Marx (2010). Para Rousseau a desigualdade econômica excessiva prejudica o exercício da cidadania, pois estimula a ganância e a busca por diferenciação social, em detrimento dos interesses gerais. Na visão de Marx - nesse ponto um discípulo original de Rousseau -, a desigualdade sob o capitalismo subordina parte das pessoas a outras; a saber, subordina aos proprietários privados dos meios de produção todas as pessoas que não são mais capazes de manter sua subsistência, sendo compelidas a venderem sua força de trabalho no mercado.

Nessa última formulação, a existência formal da cidadania política em uma sociedade na qual impera a dependência econômica entre homens e mulheres é uma espécie de farsa cuja função é legitimar o fato de que uma parte da população não tem autonomia para determinar o rumo de suas vidas. Afinal, vender a sua força de trabalho no mercado significa permitir ser utilizado como instrumento no processo produtivo, sob as ordens e sob as regras impostas pelos proprietários dos meios de produção. De acordo como essa crítica, sob dependência econômica de outrem, a liberdade prometida pelo liberalismo torna-se uma quimera, uma farsa ocultada pelas normas jurídicas.

Ambos os valores, igualdade e liberdade, gozam, segundo a visão republicana, do mesmo status e, por isso mesmo, ser cidadão significa, principalmente, ter o poder de tomar parte na criação das normas que buscam compatibilizar os dois valores, ou seja, exercitar o poder legislativo, seja pessoalmente, seja por meio de seus representantes, mesmo que tal exercício imponha limites à liberdade individual de alguns em benefício dos interesses coletivos; por exemplo, com a criação de cláusulas obrigatórias para uma série de contratos privados, com a finalidade de proteger, por exemplo, as figuras do consumidor, do trabalhador e do meio ambiente.

Para ficar em um exemplo simples: a criação de limites para o desmatamento de determinadas propriedades privadas imóveis, localizadas nas margens dos rios, visa a proteger o meio ambiente em nome do interesse coletivo, afinal, ao evitar a erosão das margens dos rios e seu consequente assoreamento, tais regras protegem a todas as pessoas dos riscos de uma eventual interrupção no fornecimento de água e da cessação da atividade de pesca.

Diante do que foi dito até aqui, parece razoável afirmar que, seja em sentido liberal, seja em sentido republicano, a cidadania oferece uma justificação para a ordem política para além dos interesses individuais dos cidadãos e cidadãs. Uma ordem política serve, evidentemente, para satisfazer os interesses dos cidadãos e cidadãs, no entanto, para além dessa dimensão, ela se destina a lhes garantir a liberdade e a igualdade, afastando o arbítrio do Estado. Explicamos. 
O poder estatal só age legitimamente caso suas ações possam ser justificadas nas leis que garantem os direitos dos cidadãos e das cidadãs. O conceito de cidadania, em sua expressão jurídica e política, permite o controle vertical do soberano pelos cidadãos e cidadãs (NIEDERBERGER, 2015, p. 85), um controle que tem sido institucionalizado, principalmente, por meio de organismos jurisdicionais. Nesse sentido, é possível propor ações judiciais em face do Estado para garantir o exercício pleno dos direitos relativos à cidadania, caso esse mesmo Estado crie obstáculos ou limites ilegais para esse exercício. Ações como o habeas corpus e o mandado de segurança, para citar apenas duas, têm como objetivo central promover o controle e a eventual invalidação dos atos ilegais praticados pelas autoridades do Estado.

Uma ordem política que reconheça a cidadania nesses termos também permite o controle horizontal das relações privadas. Afinal, como explicamos logo acima, um dos objetivos da ordem política deve ser garantir que cidadãos e cidadãs não sejam mero objeto de dominação. Ou seja, é preciso que a ordem política garanta a todas as pessoas poderes equivalentes na constituição de suas relações mútuas e na participação da produção da vontade do Estado. Sabemos que há, de fato, uma série de assimetrias de saber e de poder entre os cidadãos e cidadãs, que podem resultar no domínio privado de uns sobre os outros. Por exemplo, a desigualdade resultante do direito de herança, que pode atingir um dos valores centrais de uma ordem liberal, qual seja, a igualdade de oportunidades. Vejamos.

A depender de como a sociedade estiver organizada, uma pessoa herdeira terá mais oportunidades de formação escolar e acadêmica do que os demais cidadãos e cidadãs, além de poder empregar seus recursos na criação de empresas e negócios que podem aumentar ainda mais o seu poder econômico. Essa assimetria de poder no ponto de partida, vista da perspectiva da liberdade e do mérito individual, não se justifica adequadamente. Afinal, o fato de nascer não é mérito de ninguém: quem nasceu rico ou rica, por assim dizer, teve apenas sorte na loteria do nascimento; não empreendeu nenhuma atividade ou esforço próprio que justifiquem o gozo de vantagens de partida sobre os demais cidadãos e cidadãs.

Para evitar que distorções de meritocracia dessa natureza ocorram, é necessário estabelecer algum tipo de controle sobre as relações horizontais, com a finalidade de garantir que a liberdade e a igualdade possam ser exercitadas de fato (NIEDERBERGER, 2015, p. 86), controle que pode limitar direitos individuais; por exemplo, o direito de atribuir herança e dela gozar.

Tal necessidade se aplica também para a versão liberal da cidadania, que vê na igualdade de oportunidades um de seus elementos centrais. Para ficar no exemplo citado, é possível evitar que a desigualdade resultante da herança impeça a efetivação da igualdade de oportunidades, com a 
instituição de um imposto sobre heranças que equalize as condições iniciais para competição no mercado entre todos os cidadãos e cidadãs.

Resumindo o que foi dito até aqui, pode-se dizer que a cidadania, compreendida como a possibilidade de que todas as pessoas tomem parte na formação da vontade do Estado, resolve dois problemas políticos fundamentais. Ela fornece meios de controle vertical e horizontal do poder, impedindo que o soberano assuma um caráter arbitrário, ao impor a ele a necessidade de justificar os seus atos, e evita que as assimetrias de poder privado resultem no domínio de indivíduos ou grupos sobre os demais cidadãos e cidadãs.

A cidadania, compreendida desta maneira, está ligada necessariamente ao regime democrático e ao Estado de direito. Toda ordem política deve respeitar as leis, as quais declaram e fornecem meios de proteção aos direitos da cidadania, normalmente expressos em textos constitucionais. Todo ato de poder deve ser justificado nas leis, produzidas com a participação de todos os cidadãos e cidadãs. Além disso, não pode haver mais nenhuma fonte legítima de produção de normas gerais além do poder do Estado, para que fique afastada a possibilidade de se configurarem situações de dominação privada de um cidadão pelo outro. Exercer o poder só é possível com fundamento nas regras produzidas pela vontade de todas as pessoas.

Em seu estudo clássico sobre o assunto, T. H. Marshall mostrou que as diversas concepções de cidadania são objeto de disputas ao longo do tempo, especialmente em sociedades marcadas por desigualdades de classe. Como mostra o autor, a cidadania é um status de igualdade concedido a todas as pessoas, membros de uma comunidade política, para a sua participação integral nessa comunidade. De outro lado, a classe é uma marca de desigualdades econômicas (MARSHALL, 1977, p. 62). São os conflitos entre as classes, pela participação na comunidade política, que vão formatando as diversas configurações históricas da cidadania, marcadas pela aquisição paulatina de direitos civis, políticos e sociais.

Os direitos civis, na formulação clássica de Marshall, são aqueles que se referem à liberdade individual, ao direito de ir e vir, à liberdade de imprensa, pensamento e fé, à propriedade e ao acesso à justiça. Tais direitos formam a base da versão liberal da cidadania. Já os direitos políticos são aqueles que garantem a participação no exercício do poder político, ou seja, o direito de votar e de ocupar cargos públicos.

Todos estes direitos, diga-se, não foram conquistados prontamente por todas as classes sociais, como mostra Marshall, afinal, sempre constituíram uma ameaça clara aos interesses das classes proprietárias (MARSHALL, 1977, p. 85). Eleitos, os representantes de classes desfavorecidas poderiam ameaçar a posição econômica das classes proprietárias, ao influenciar a criação de leis de 
acordo com seus interesses. Os direitos sociais, surgidos no século XX, são um exemplo claro disso, pois oferecem a todos os cidadãos e cidadãs um certo patamar de igualdade econômica e de segurança, inclusive o direito à educação e à saúde. Criam limites claros à livre iniciativa, especialmente à liberdade de contratar trabalho. Os direitos civis e os direitos políticos, diga-se, também podem ameaçar o poder, ao permitir a qualquer cidadão ou cidadã resistir aos atos do poder e tomar parte no processo de criação de leis.

Vale lembrar também que a sequência de criação desses direitos variou historicamente de país para país (CARVALHO, 2002). No caso do Brasil, por exemplo, os direitos civis e políticos sofreram restrições nos diversos momentos em que estiveram vigentes regimes autoritários. Já os direitos sociais tiveram seu marco inicial de implementação na década de 30, momento em que o País estava dominado por um regime autoritário e, décadas depois, foram aprofundados pela Constituição de 1988, que marca a saída do País da ditadura militar implementada em 1964.

Retomando o fio da exposição, não foi por outra razão que Franz Neumann, algumas décadas antes de Marshall, afirmou que o Estado de direito pode ter efeitos revolucionários em sociedades desiguais (NEUMANN, 2013; RODRIGUEZ, 2013). Para Neumann, um Estado de direito permite, em funcionamento, que os diversos interesses sociais busquem conquistar a forma de direitos, de modo a ampliar o conteúdo da cidadania, para que ela leve em conta os interesses e necessidades dos diversos agentes sociais, agentes que não param de surgir ao longo da história.

O Estado de direito tem como fundamento de legitimidade, justamente, a promessa de governar levando em conta os interesses e necessidades de todas as pessoas. Por isso mesmo, qualquer indivíduo ou grupo que se sinta tratado de forma desigual pode utilizar a gramática da cidadania para reivindicar direitos que sejam capazes de levá-los a uma igualdade de condição com os demais. É razoável dizer, portanto, que, em sociedade desiguais, a cidadania também está na base de processos de transformação social.

\section{CIDADANIA, REPRESENTAÇÃO E PARTICIPAÇÃO}

A possibilidade de participar da formação das regras que compõem a ordem política tem se dado, principalmente, por meio do voto, ou seja, pela eleição periódica de representantes do povo para ocupar os cargos na estrutura do Estado. A necessidade de eleger representantes, explica Max Weber (1993), está relacionada ao desenvolvimento das sociedades de massa e de mercado que promovem um aumento no número de pessoas vivendo em sociedade e aumentam o tempo de trabalho destinado à sobrevivência. 
Em sociedades organizadas desta maneira é impossível reunir todos os cidadãos, ao contrário do que se fazia na ágora em Atenas (naquele caso, exclusive escravos e mulheres), para debater os problemas da cidade. O tempo de trabalho necessário para garantir a sobrevivência de cada um torna impossível o exercício da política pela participação direta de todos os cidadãos e cidadãs. Em “Política como Vocação”, texto em que trata desses problemas, Weber (1993) menciona, a esse propósito, o exemplo de um médico, incapaz de exercer a sua função e fazer política ao mesmo tempo.

Por todas essas razões, surge nos Estados nacionais uma classe de políticos profissionais que exercem a atividade política em tempo integral e disputam periodicamente o voto dos cidadãos e cidadãs, com todos os riscos inerentes a essa inovação, discutidos por Weber em seu texto. Afinal, ao delegar a política para profissionais, a sociedade abre a possibilidade de que seus representantes ponham a permanência em seus cargos, o acesso a seus empregos, acima da atividade de representar a sociedade e passem a viver da política e não para a política.

A cidadania nos tempos atuais parece não poder escapar, portanto, do instituto da representação, mesmo que temperado com mecanismos de participação direta. Em uma sociedade complexa, com tempo livre limitado e jornadas de trabalho extensas, existe um entrave estrutural para a participação direta de cidadãos e cidadãs na atividade política.

Com efeito, na explanação de Nadia Urbinati (2006), a representação pode ser exercida de duas maneiras diferentes, a depender do modo pelo qual o representante e a sociedade pensam a relação entre representação e democracia. A pessoa do representante pode ser vista como parte em um contrato celebrado com seus eleitores: trata-se do modelo jurídico da representação. Essa maneira de ver a representação parte do pressuposto de que a sociedade é composta de indivíduos portadores de determinados interesses conflitantes entre si e o momento da eleição serve para que eles disputem competitivamente os votos disponíveis. Ao elegerem seus representantes, cidadãos e cidadãs passam a esperar que eles façam valer esses interesses em seu âmbito de atuação, cumprindo o contrato celebrado por meio do voto e referendado pelas urnas (URBINATI, 2006, p. 192).

O modelo jurídico configura a relação entre representado e representante conforme as linhas de uma lógica individualista e não política, pois supõe que os eleitores julguem as qualidades pessoais dos candidatos, em vez de suas ideias políticas e projetos. Dessa forma, a representação não é e nem pode ser um processo, tampouco pode ser uma matéria política que implique, por exemplo, uma demanda por representatividade ou representação justa, pela simples razão de que a representação é, por definição, qualquer coisa que feita mediante o tipo correto de autorização e dentro de seus limites.

Esse modelo de representação está fundado em um dualismo bem definido entre Estado e sociedade, o que faz da representação um instituto centrado rigorosamente no Estado, cuja relação 
com a sociedade é deixada ao juízo do representante. Ainda, esse modo de conceber a representação restringe a participação popular a um mínimo procedimental, qual seja, as eleições compreendidas como meio de escolha e nomeação dos representantes (URBINATI, 2006, p. 198).

Essa visão da democracia e da representação pensam o instituto em termos de vencedores e perdedores, ou seja, os vencedores da eleição devem levar adiante os interesses de seus representados, cumprindo seu contrato com eles, em detrimento do restante da sociedade. Nessa lógica de funcionamento, a representação pode levar a situações em que o vencedor leva tudo, mesmo que a diferença de votos entre os competidores seja pequena. Afinal, os eleitos e as eleitas não irão governar para a sociedade como um todo, levando em conta seus interesses conflitantes, pois o voto não representa ideias gerais, mas sim interesses deste ou daquele grupo (URBINATI, 2006, p. 212).

Uma visão deliberativa de representação caminha em outro sentido. Para esta visão, a representação é concebida como um processo, um diálogo participativo entre representante e representados. A representação não pertence apenas aos agentes ou instituições governamentais, mas designa um processo político estruturado nos termos da circularidade entre as instituições e a sociedade. Nesse sentido, a representação não é confinada à deliberação e decisão apenas no momento do voto, mas implica um processo contínuo de debate com as forças sociais em uma constante redefinição de seus objetivos (URBINATI, 2006, p. 212).

Esta visão da representação defende que, em um governo que deriva sua legitimidade a partir de eleições livres e regulares, a ativação de uma corrente comunicativa entre a sociedade civil e o sistema político é essencial e constitutiva da atividade política. As múltiplas fontes de informação e as variadas formas de comunicação e influência que os cidadãos ativam por intermédio da mídia, movimentos sociais e partidos políticos devem dar o tom da representação em uma sociedade democrática.

Nessa ordem de razões, a representação política não elimina o povo de seu exercício, mas despreza a ideia de que os eleitores, em vez dos cidadãos, ocupem este centro. Para a representação compreendida como deliberação, o ato de autorização não deve ser mais importante do que o processo político de deliberação que liga representantes e representados de maneira contínua e ajuda a definir, assim, o conteúdo da cidadania, com a criação e a eventual revogação de direitos.

\section{DESAFIOS DA CIDADANIA NO MUNDO CONTEMPORÂNEO}

O momento atual põe uma série de desafios para a cidadania, tanto no que diz respeito à sua dimensão de controle do poder e de pertencimento a uma ordem política, quanto à sua capacidade de 
legitimar e promover a participação dos cidadãos e cidadãs na criação das normas que regulam suas vidas.

Em primeiro lugar, como afirma Andreas Niederberger (2015, p. 89), assistimos a um aumento significativo no número de pessoas que vivem de forma mais ou menos temporária em um determinado território, estão sujeitas à sua respectiva ordem política, mas não são consideradas cidadãs - por exemplo, trabalhadores e trabalhadoras temporárias. Segundo, os cidadãos e cidadãs das diversas ordens políticas estão hoje sujeitos ao efeito de normas que não foram produzidas pelos Estados em que estão situados; normas sobre as quais, muitas vezes, nem sequer seus Estados têm poder de influência. Nesse caso, é o poder de legislar, supostamente garantido pelo status de cidadão, que fica comprometido.

Um bom exemplo deste segundo fenômeno está nas assim denominadas, por Gunther Teubner (2013), ordens privadas transnacionais. Teubner mostra que uma série de normas de caráter privado destinadas a regular temas como a internet, o futebol mundial e o comércio internacional, começa a reivindicar aplicação sobre todo o globo, mesmo sem ter sido aprovada pelos Estados nacionais. As assim denominadas lex digitalis, lex FIFA e lex mercatoria, para citar apenas três exemplos, têm efeitos sobre os cidadãos e cidadãs dos vários Estados nacionais, mesmo que eles e elas não tenham a oportunidade de participar de sua elaboração e de influenciar sua eventual modificação.

E estes são apenas três exemplos de normas criadas por organismos privados que regulam uma série de atividades e relações de alcance transacional, da qual tomam parte agentes sociais determinados, nem todos capazes de influenciar a criação dessas normas. Tais ordens privadas transnacionais contribuem para diminuir o alcance e a relevância do poder legislativo dos Estados nacionais e, como consequência, do poder da democracia e dos cidadãos e cidadãs que participam desses Estados. Afinal, as referidas ordens privadas transnacionais regulam de fato uma série de atividades e fenômenos que antes eram regulados exclusivamente pelas normas estatais.

Podemos imaginar que a solução para o problema dos habitantes transitórios de um certo território poderia consistir na concessão de algum poder de influência a todas as pessoas que sofrem os efeitos de uma determinada ordem política, mesmo que elas não sejam consideradas cidadãs dessa ordem. No entanto, esta solução apresenta a dificuldade de passar por cima dos laços simbólicos e identitários que ligam os cidadãos e seus respetivos Estados. Conceder poder de influência em uma determinada ordem política a um habitante transitório pode significar atribuir um status muito semelhante ao de um cidadão a pessoas que não são vistas como membros daquela ordem (NIEDERBERGER, 2015, p. 89). 
O segundo problema que mencionamos é ainda mais difícil de resolver diante da impossibilidade de remeter a cidadania para uma ordem política mais ampla, supostamente capaz de impor limites a todas as ordens normativas existentes (NIEDERBERGER, 2015, p. 90). A multiplicação de ordens políticas de níveis os mais diversos - local, nacional, regional, internacional e transnacional - dificulta a criação de estruturas capazes de articular e coordenar toda essa complexidade normativa. Afinal, uma boa parte das normas no mundo de hoje parece mesmo estar migrando para ordens normativas que funcionam em paralelo à ordem estatal, tendo como protagonistas agentes privados como empresas, agremiações esportivas, agências de risco e agentes financeiros, entre outros.

O resultado é que nossas vidas passam a ser afetadas por normas de origens as mais diversas, em relação às quais assumimos posições muito diferentes, nem sempre a de cidadãos e cidadãs dotadas do poder de influir decisivamente sobre a sua criação. Por exemplo, um torcedor de futebol suporta os efeitos das normas da FIFA, que determinam o modo de funcionamento de uma série de campeonatos ao redor do mundo. Tais normas, inclusive, preveem sanções aos times em razão do comportamento de sua torcida, os quais não têm voz alguma na criação ou alteração dessas regras.

Da mesma maneira, um usuário da internet sofre os efeitos de uma série de normas produzidas por agências variadas que regulam as diversas dimensões da rede; por exemplo, o funcionamento dos provedores de internet, o registro dos sites, o tipo de conteúdo que pode ser publicado nas redes sociais e assim por diante. Em vários desses casos, de pouco adianta ser cidadão ou cidadã de um Estado nacional, pois tal status não tem poder algum sobre a produção dessas normas.

Um terceiro problema enfrentado pela cidadania no mundo de hoje é sua perda de importância em vários Estados nos quais esse status não garante poder de influência sobre a produção das normas ou o acesso a bens, serviços e direitos (NIEDERBERGER, 2015, p. 90). A transferência de poder para comitês e organismos técnicos torna cada vez mais difícil identificar os locus onde são tomadas as decisões sobre os mais diversos assuntos. Para dizer o mínimo, o parlamento não é mais o único espaço onde normas relevantes para as nossas vidas são criadas.

Ademais, como mostra com clareza Streeck (2013), a expansão do capitalismo financeiro e o crescente endividamento dos Estados nacionais criam limites para a expansão dos direitos sociais e para a expansão da cidadania em geral. A necessidade de financiar a dívida dos Estados (nos bancos) faz com que eles passem a trabalhar para dois senhores ao mesmo tempo.

De um lado, os financiadores da dívida pública fazem exigências de austeridade fiscal e contenção crescente de gastos, e, de outro, os cidadãos e cidadãs continuam articulando novas 
demandas por direitos. Esse estado de coisas, qual seja, o compromisso necessário dos Estados com os organismos financeiros, vai deixando cada vez mais claro para os cidadãos e cidadãs que seu poder para determinar as regras que regulam a sua própria vida se encontra limitado, mesmo que seus candidatos saiam vencedores nas eleições; um fato que, na opinião de Streeck (2013), abre uma grave crise para os regimes democráticos ao redor do mundo.

Além disso, uma série de medidas recentes tem diminuído a importância da cidadania mesmo em seu sentido liberal clássico, como, por exemplo as leis de combate ao terrorismo. Essa legislação, em nome de combater o risco de ataques, tem relativizado uma série de direitos fundamentais na investigação e persecução de possíveis delitos, ao prever uma série de normas que ampliam as hipóteses de detenção e prisão, sem as garantias tradicionais do devido processo legal, criando hipóteses de investigação com quebra do sigilo de informações pessoais e chegando ao limite de prever a possibilidade de eliminar fisicamente cidadãos e cidadãs em nome da assim denominada “guerra ao terror” (NIEDERBERGER, 2015, p. 91).

Um quarto problema enfrentado pela cidadania no mundo de hoje é o fato de que ela não é mais a única arena na qual a sociedade disputa sua forma de vida e seu projeto de futuro. A ordem política é pensada pelos seus membros como um instrumento de proteção de interesses individuais, mas nem sempre como um instrumento para realizar objetivos coletivos.

Por exemplo, em alguns países há uma forte tendência de se recorrer ao Judiciário com a finalidade de transformar as normas que compõem a ordem política, sem fazer as demandas passarem pelo processo de votação e participação política (NIEDERBERGER, 2015, p. 92), questão que no Brasil tem sido debatida sob a denominação equívoca de “judicialização da política” (NOBRE; RODRIGUEZ, 2011). Em razão desse fenômeno, a criação das normas que regulam a vida em sociedade deixa de ser protagonizada apenas pelo Parlamento e passa a contar com a participação do Poder Judiciário, fato que contribui para retirar a centralidade das eleições no exercício do Poder Legislativo.

\section{ALTERNATIVAS PARA A CIDADANIA}

Há algumas propostas na mesa que procuram dar conta dos problemas que acabamos de elencar. São elas, na síntese de Niederberger (2015, p. 93), a cidadania cosmopolita, a participação política sem cidadania e a cidadania-constelação. Examinemos cada uma delas, ainda que sucintamente. 
A proposta de uma cidadania cosmopolita tem sido defendida por David Held e Daniele Archibugi e consiste em manter em funcionamento a cidadania tradicional, ligada aos Estados nacionais, acrescentando uma nova dimensão à cidadania; uma dimensão suplementar à cidadania doméstica e que tem como finalidade suprir as suas deficiências. Sob a égide da cidadania cosmopolita ficariam garantidos aos indivíduos tanto o status de cidadão de seus Estados quanto a possibilidade de participar de organismos internacionais e organismos jurisdicionais de alcance global.

A cidadania cosmopolita incluiria, portanto, o direito dos indivíduos de processar Estados em tribunais internacionais, regular eventuais influências indevidas ou conflitos entre ordens políticas nacionais, obter recursos para lidar com catástrofes que envolvam refugiados, entre outras medidas que se imponham para além das fronteiras nacionais. Tal cidadania seria um complemento da cidadania doméstica, pois lidaria com problemas os quais esta não tem condições de lidar por ultrapassarem seu âmbito natural de atuação (NIEDERBERGER, 2015, p. 93-94).

Esta proposta enfrenta uma série de dificuldades. Para começar, a inexistência de instituições capazes de efetivar os direitos prometidos por ela. Afinal, hoje não existem, de fato, organismos internacionais ou tribunais capazes de suprir as deficiências da cidadania doméstica. Não existem no âmbito internacional instituições formais suficientemente poderosas para impor normas obrigatórias para todos os países e indivíduos ao redor do globo. Além disso, mesmo que instituições assim existissem, elas poderiam rapidamente assumir caráter tirânico, caso deixassem de levar em conta a vontade dos Estados e dos cidadãos e cidadãs de cada localidade.

Ademais, não é fácil identificar com clareza o que são questões de interesse regional e o que seriam questões de interesse cosmopolita. Muitas vezes a divergência que se instaura entre os agentes sociais diz respeito, justamente, a discordâncias quanto ao âmbito de relevância de um determinado problema - por exemplo, nos casos que envolvem uma possível intervenção humanitária de organismos internacionais em países envolvidos em conflitos internos ou em guerras. A hierarquia entre a ordem doméstica e a ordem cosmopolita não se apresenta, assim, de forma evidente a ponto de permitir decisões inequívocas sobre as eventuais providências a tomar.

A segunda proposta em debate, na formulação de Niederberger, é a ideia de participação política sem cidadania. De acordo com esta proposta, seria garantido a todas as pessoas afetadas por uma determinada ordem normativa a possibilidade de dela participar. Assim, bastaria que alguém fosse afetado por uma determinada decisão para ter a possibilidade de influir sobre ela, como se essa pessoa fosse um cidadão ou cidadã daquela ordem política (NIEDERBERGER, 2015, p. 94-96). 
Há uma dificuldade evidente nesta proposta: ela ignora que diversas questões decididas no âmbito de uma ordem normativa dependem de uma colaboração de longo prazo entre os cidadãos. Por exemplo, o acesso aos benefícios garantidos pelos direitos sociais exige a criação de toda uma estrutura de arrecadação, organizada pelos Estados nacionais com o objetivo de financiar coletivamente os diversos programas sociais.

A revisão constante dos membros de uma ordem política, neste caso, poderia pôr a perder a viabilidade de oferecer tais benefícios; afinal, tal variação afetaria tanto o seu financiamento quanto a demanda por novos benefícios sociais. Além disso, esta proposta poderia ser aplicada apenas a sistemas fechados, bem localizados territorialmente. Ora, como já vimos, há uma série de ordens normativas que transcendem as fronteiras dos Estados e, portanto, não poderia funcionar nos termos da proposta de concessão de direitos de participação política sem cidadania.

Outra versão desta mesma ideia, chamada de cidadania transnacional (NIEDERBERGER, 2015, p. 95), foi elaborada por David Owen e advoga a possibilidade de que qualquer um possa participar das estruturas e instituições que tenham influência sobre sua vida e tenha acesso aos sistemas de cooperação, desde que esteja disposto a arcar com seus custos e com os deveres que eles impõem.

Esta proposta também é de difícil implementação; afinal, não há como diferenciar com clareza a participação política da cidadania propriamente dita. Por isso mesmo, oferecer a possibilidade de participar nesses moldes equivaleria a equiparar o beneficiado ou beneficiada aos cidadãos e cidadãs de um determinado Estado, o que teria implicações simbólicas e identitárias indesejadas. Além disso, essa proposta parece dar conta apenas do caso de pessoas que circulam ao redor do mundo, pessoas que podem entrar e sair do âmbito de influência de ordens políticas claramente identificadas. A cidadania transnacional não dá conta do fato de que as ordens políticas e normativas tendem a se sobrepor umas às outras e, muitas vezes, a entrar em conflito.

Finalmente, Niederberger menciona a proposta de Roger Bauböck, a cidadania-constelação (NIEDERBERGER, 2015, p. 95-96), antes de apresentar a sua solução, elaborada a partir dela. A cidadania-constelação parte do pressuposto de que existem ordens políticas plurais dispostas em níveis diferentes, a saber, local, regional, nacional, internacional, transacional e assim por diante. Para esta visão da cidadania, as pessoas podem ser cidadãs de várias ordens ao mesmo tempo, sendo titulares, por conseguinte, de múltiplas cidadanias.

Portanto, deveria haver várias maneiras de influir e de controlar as ordens políticas e normativas. De acordo com algumas delas, será possível participar diretamente da política e, assim, da formação das normas. Em outras, por outro lado, a pessoa será titular de um status limitado e 
derivado de sua participação em outra ordem política, o que poderia abrir a ela a possibilidade de controlar apenas alguns efeitos das normas que influenciam a sua vida, mas não de participar de maneira completa do processo político.

Por exemplo, pode-se imaginar a possiblidade de garantir a todas as pessoas, mesmo aquelas que não sejam cidadãos e cidadãs plenas de um determinado Estado, a possiblidade de votar e opinar em nível local; por exemplo, em questões relativas à região ou à cidade onde moram. Desse modo, múltiplas formas de cidadania e de pertencimento a ordens normativas poderiam coexistir, garantindo a todas as pessoas a possibilidade de influir sobre as normas que afetam as suas vidas.

Para Andreas Niederberger, a possibilidade de efetivar esta proposta de cidadania exigiria a construção de dois tipos de instituições formais. De um lado, teríamos ordens políticas singulares em funcionamento, dotadas de instituições que deveriam ser capazes de garantir condições não arbitrárias de funcionamento. De outro lado, seria necessário edificar estruturas e instituições de segunda ordem, capazes de garantir que tais ordens políticas não dominem umas às outras e que não se tornem internamente arbitrárias (NIEDERBERGER, 2015, p. 98).

As ordens políticas singulares, segundo esta proposta, deveriam garantir para todas as pessoas a possibilidade de participar da formação de suas normas e construir mecanismos judiciais que garantam o seu cumprimento. As mencionadas estruturas de segunda ordem, por sua vez, deveriam ter alcance regional ou global e capacidade de intervir sobre aquelas ordens políticas singulares que passarem a funcionar de maneira arbitrária, seja porque:

a) elas se tornaram internamente arbitrárias - por exemplo, em caso de violação de direitos humanos;

b) elementos de uma ordem passaram a dominar outra, promovendo interferências arbitrárias - por exemplo, no caso da externalização de danos ecológicos;

c) os indivíduos não conseguem agir em condições não arbitrárias - por exemplo, quando há pessoas vivendo em situação de guerra civil ou em Estados totalmente desarticulados;

d) há situações em que a revisão de certos elementos da ordem normativa pode aumentar seu carácter não arbitrário - por exemplo, pela manutenção de administrações custosas em locais diferentes (NIEDERBERGER, 2015, p. 99-100).

Para o autor, tais estruturas de segunda ordem deveriam ter a forma de mecanismos judiciais, os quais assumiriam funções semelhantes àquelas exercidas pelo Poder Judiciário nacional, mas tendo como objeto as diversas ordens políticas singulares em funcionamento no espaço global (NIEDERBERGER, 2015, p. 100). Como é amplamente sabido, uma das funções do Poder Judiciário é verificar se determinados comportamentos se adequam ou não às normas jurídicas e, além disso, no 
contexto de algumas ordens políticas, exercer o controle constitucional com a finalidade de examinar a adequação de determinadas normas e instituições às normas constitucionais.

Em uma estrutura como esta, os cidadãos e cidadãs poderiam construir livremente ordens políticas em múltiplos níveis, desde que elas não dominassem umas às outras e funcionassem de forma não arbitrária. Haveria, portanto, uma pluralidade de comunidades políticas heterogêneas, cada uma tratando de problemas e assuntos diferentes, por meio das quais as pessoas poderiam colaborar para realizar os mais diferentes objetivos, utilizando-se, para esta finalidade, das mais variadas modalidades de participação política.

Como se vê, a reinvenção da democracia exige, nesses termos, uma revisão no modo pelo qual olhamos para as ordens políticas singulares, uma perspectiva que deve fugir da visão tradicional, centrada em Estados nacionais, os quais poderiam vir a formar uma possível sociedade mundial. De acordo com a proposta de cidadania-constelação, a visão da democracia centrada nos Estados deve ser deixada de lado. A pluralidade política de ordens normativas exige o reconhecimento de múltiplas formas de pertencimento, mantido o caráter não arbitrário do funcionamento dessas diversas ordens normativas e uma relação de não dominação entre elas, garantida por estruturas judiciais de alcance regional e global.

\section{CONCLUSÃO}

A cidadania precisa se transformar para manter a centralidade na gramática da política contemporânea, tendo em vista as mudanças sociais ocorridas no final do século XX e neste começo de século XXI. Tais mudanças abalaram a centralidade dos Estados nacionais como fonte das regras que influenciam a vida das pessoas, em razão da globalização das finanças e da criação de ordens normativas de outra natureza, e criaram situações de moradia transitória e de circulação de pessoas que estão contribuindo para a relativa obsolescência do conceito de cidadania. Além disso, problemas como o combate ao terrorismo estão levando à relativização de uma série de direitos típicos da cidadania, supostamente em favor do incremento da segurança.

Ser cidadão de um Estado nacional significa, tradicionalmente, pertencer a uma determinada comunidade política, e, por isso mesmo, ser levado em conta na criação das regras que presidem a vida em sociedade e ter acesso a uma série de direitos e benefícios. Pelas razões discutidas neste texto, todas essas dimensões da cidadania estão sendo ameaçadas, o que faz com que o conceito perca a centralidade na descrição do status político dos homens e mulheres que vivem ao redor do globo. 
Para manter a centralidade do conceito, Andreas Niederberger examina diversas concepções de cidadania presentes no debate acadêmico contemporâneo e propõe a ideia da cidadaniaconstelação, que admite diversas formas de pertencimento às variadas ordens normativas singulares existentes e propõe a criação de instituições de tipo jurisdicional com poder para manter essas ordens funcionando em padrões democráticos e para evitar que uma ordem ameace colonizar a outra.

Essa proposta tem como finalidade manter em funcionamento a estrutura básica do conceito de cidadania, que é capaz de garantir participação na criação das regras que presidem as nossas vidas e o acesso a uma série de direitos e benefícios. A alternativa seria a fragmentação das ordens normativas e a eventual colonização de umas por outras. Fica claro, neste ponto, o caráter normativo da proposta de Niederberger, uma proposta que tem como objetivo conservar os ganhos democráticos do conceito de cidadania normativa sem deixar de levar em conta as transformações sociais contemporâneas.

\section{REFERÊNCIAS}

CARVALHO, José Murilo de. Cidadania no Brasil: o longo caminho. Rio de Janeiro: Civilização Brasileira, 2002.

MARSHALL, T. H. A. Cidadania, classe social e status. Rio de Janeiro: Zahar, 1977.

MARX, Karl. Sobre a questão judaica. São Paulo: Boitempo, 2010.

NEUMANN, Franz. O império do direito. Quartier Latin: São Paulo, 2013.

NIEDERBERGER, Andreas. Citizenship, Democracy and the Plurality of Means, Forms and Levels of Participation. In: CELIKATES, Robin; KREIDE, Regina; WESCHE, Tilo (Org.). Transformations of Democracy: Crisis, Protest and Legitimation. London: Rowman \& Littlefield, 2015.

NOBRE, Marcos; RODRIGUEZ, José Rodrigo. "Judicialização da política”: déficits explicativos e bloqueios normativistas. Novos Estudos - CEBRAP, São Paulo, n. 91, p. 5-20, 2011.

RODRIGUEZ, José Rodrigo. A desintegração do status quo: direito e lutas sociais. Novos Estudos - CEBRAP, n. 96, p. 49-66, 2013.

ROUSSEAU, Jean-Jacques. Discurso sobre a origem e os fundamentos da desigualdade entre os homens. Brasília: Editora Universidade de Brasília, 1989.

STREECK, Wolfgang. Tempo comprado - A crise adiada do capitalismo democrático. Coimbra: Actual, 2013. 
TEUBNER, Gunther. A bukowina global sobre a emergência de um pluralismo jurídico transnacional. Impulso, Piracicaba, v. 14, n. 33, p. 9-31, 2013.

URBINATI, Nadia. O que torna a representação democrática? Lua Nova, n. 67, p. 191-228, 2006.

WEBER, Max. Política como Vocação. In: WEBER, Max. Ciência e política: duas vocações. São Paulo: Ed. Cultrix, 1993.

José Rodrigo Rodriguez Bacharel (1995) e Mestre (2001) em Direito pela Universidade de São Paulo. Doutor em Filosofia (linha Teoria do Direito e do Estado) pela Universidade Estadual de Campinas (2006). Professor na Unisinos (Graduação, Mestrado e Doutorado) e pesquisador permanente, ligado ao Núcleo Direito e Democracia, no Cebrap. E-mail: jrodrigorodriguez@gmail.com 